\title{
The use of photovoice in evaluating a community-based rehabilitation (CBR) program: experiences from CBR volunteers in Namibia
}

\author{
Tonderai Washington Shumba
}

Department of Public Health Policy and Management, School of Public Health, University of Namibia, Windhoek, Namibia

Desderius Haufiku

Department of Environmental and Occupational Health, School of Public Health, University of Namibia, Windhoek, Namibia, and

\author{
Hans Amukugo \\ Department of Community Nursing, University of Namibia, \\ Windhoek, Namibia
}

\begin{abstract}
Purpose - Qualitative participatory methods are needed to measure the effectiveness of the community-based rehabilitation (CBR) program in Namibia. The study explored the experiences of $\mathrm{CBR}$ volunteers in evaluating CBR program in Namibia through the use of photovoice. Further the study assessed the strengths and limitations of utilizing photovoice method as an assessment tool for CBR evaluation.

Design/methodology/approach - The study employed a qualitative, explorative, descriptive and contextual design. Data was collected through the photovoice method. Two CBR sites and 16 participants who were CBR volunteers were purposively selected. Data was collected and analysis was conducted simultaneously utilizing the photovoice method and themes were determined using WHO CBR matrix.

Findings - Various experiences were elicited regarding participants' experiences in line with the five components of the CBR matrix. Most experiences were reported regarding the health component, and the education component had the least experiences reported. Methodological strength and weaknesses as well as implications for practice are revealed. Further research can explore the benefits of combining photovoice with other data collection methods.

Originality/value - Sustainability of CBR programs depends on community ownership, empowerment and government funding. Photovoice is participatory and hence gives community ownership and empowerment.
\end{abstract}

(c) Tonderai Washington Shumba, Desderius Haufiku and Hans Amukugo. Published in Journal of Health Research. Published by Emerald Publishing Limited. This article is published under the Creative Commons Attribution (CC BY 4.0) license. Anyone may reproduce, distribute, translate and create derivative works of this article (for both commercial and non-commercial purposes), subject to full attribution to the original publication and authors. The full terms of this license may be seen at http:// creativecommons.org/licences/by/4.0/legalcode

The authors would like to thank the participants for their time and officials of the Department of Disability Affairs, Office of the Presidency for assisting with data collection.

Disclaimer: The views expressed in the submitted article are the authors' own and not an official position of the institution or funder.

Source(s) of support: This project was funded by the University of Namibia, School of Public Health

Authors' contributions: T.W.S was the project leader responsible for project design, data collection and preparation of final report. D.H and H.A made conceptual contributions and contributed to preparation of final report.

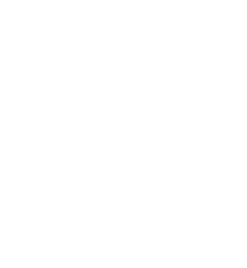


JHR

35,3

Evidence from photovoice can enable persons with disabilities to formulate action plans that can advocate their concerns with policymakers and justify more funding for CBR programs.

Keywords Community-based rehabilitation, Disability, Photovoice, Namibia

Paper type Research paper

\section{Introduction}

Soon after Namibia's independence in 1990, UNICEF, in collaboration with the Repatriation, Resettlement and Reconstruction Committee of the Council of Churches in Namibia, established an intergraded area-based program (IABP) in Uukwaluudhi, in the Omusati region. The major objectives of the IABP were to empower the community to promote the rehabilitation of children with disabilities. This introduction of IABP gave birth to the concept of community-based rehabilitation (CBR) that was then initiated in Namibia in 1992 [1] and adopted in 1997 as the main strategy for rehabilitation [2]. To date, the CBR program has been rolled out to all 14 regions in Namibia.

The Ministry of Health and Social Services (MOHSS) is the custodian for the delivery of disability and rehabilitation services. CBR programs are administered through rehabilitation workers at the district level with the assistance of CBR volunteers at various health centers, clinics, outreach points, social welfare service points and the community.

A review of policies, legislation and programs related to persons with disabilities in Namibia [3] identified that CBR underpins all policies and legislation as a key strategy for providing rehabilitation services in Namibia [2]. Nevertheless, its effectiveness has not been assessed from the perspective of persons with disabilities but is often interpreted by service providers as a tool to deal with "problems" of persons with disabilities and thus fails to allow persons with disabilities to enjoy equal rights [4]. To this end, a review of both implementers and recipients of the services [5] confirmed that there is a need for participatory evaluation methods in CBR.

To date, quantitative data has dominated CBR evaluation in Namibia. The only qualitative methods that are conducted are face-to-face-interviews with CBR volunteers merely for monitoring activities and not for evaluation.

Considering the low literacy rate among persons with disabilities, we investigated practical methods that could be used to evaluate the qualitative aspects of the CBR program from experiences of persons with disabilities and established [6] that the photovoice method has the potential to effectively elicit the experiences of persons with disabilities on a CBR program.

This current study aimed to explore the experiences of CBR volunteers in CBR programming in Namibia as well as to assess the strengths and limitations of utilizing the photovoice method as an assessment tool for CBR programming.

\section{Methods}

A qualitative, descriptive, explorative and contextual design was employed.

\section{Study sites}

Sites from two different geographical areas were selected. These sites included the Otavi CBR program in Otjozondjupa Region and the Stampriet CBR program in Hardap Region. The two sites were selected to ensure diversity in traditional structures, tribal influence and geographical terrains. The Otjozondjupa region mainly comprises the Otjiherero-speaking tribe and in Hardap the tribes mainly speak Nama and Damara. Otavi has a CBR program set up in a small town while in contrast, Stampriet's CBR program has a rural village setting. Both CBR sites have a terrain that is fairly accessible to persons with disabilities. 
Study sample and selection strategy

Purposive sampling was used to identify key participants for the two study sites and a sample size of eight participants per site was used. A Senior Rehabilitation Officer in each region was chosen as a research assistant to assist in each site. To control for selection bias of participants, a research assistant with CBR experience of the program area and who could speak the local language was recruited.

The research assistant chosen was the Senior Rehabilitation Officer, who assisted in selecting the participants and the CBR program area. To control for selection bias of participants, the following inclusion and exclusion criteria as described were used:

Inclusion criteria for the senior rehabilitation officer (research assistant)

(1) Have at least three years of CBR experience,

(2) Have at least two years of working in the CBR program of that region,

(3) Be able to speak the local language of that area.

\section{Inclusion criteria for participants}

(1) Above 18 years of age,

(2) Experiential participants, that is, a person with a disability or a caregiver of a person with a disability,

(3) Able to use a camera and describe his/her photographs,

(4) Involvement in the CBR program for at least one year,

(5) Have basic advocacy skills to be able to engage in dialogue that can influence policy and decision-making,

(6) Be able to read and speak basic English,

(7) Must be willing and interested in participating in the project for one month,

(8) Must be willing to share their experiences with participant group members and eventually the public.

\section{Exclusion criteria for participants}

(1) Below 18 years of age,

(2) Individuals with intellectual disabilities or mental illness/emotional disorders,

(3) Individuals who are highly dependent on medical care,

(4) HIV-positive and previous traumatic war experiences or stressful life circumstances.

Inclusion criteria for the CBR program area

(1) A rural area with poor access,

(2) A CBR program area running for at least two years,

(3) Area with active CBR volunteers.

Data collection and analysis

Data collection and analysis were conducted simultaneously in seven steps utilizing a modified photovoice process by Shumba and Moodley [7], ( Table 1). photovoice in evaluating

CBR program 


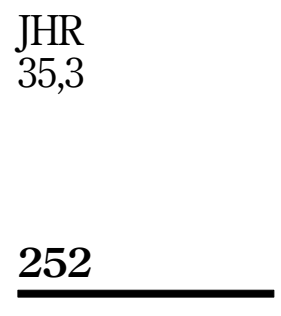

Table 1.

Procedure for data collection and analysis

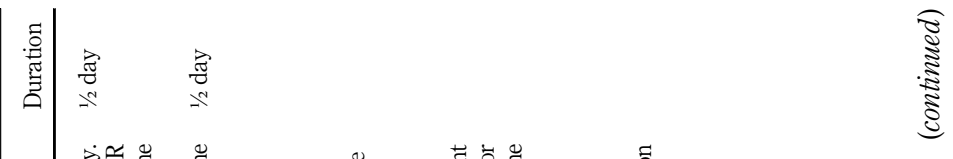

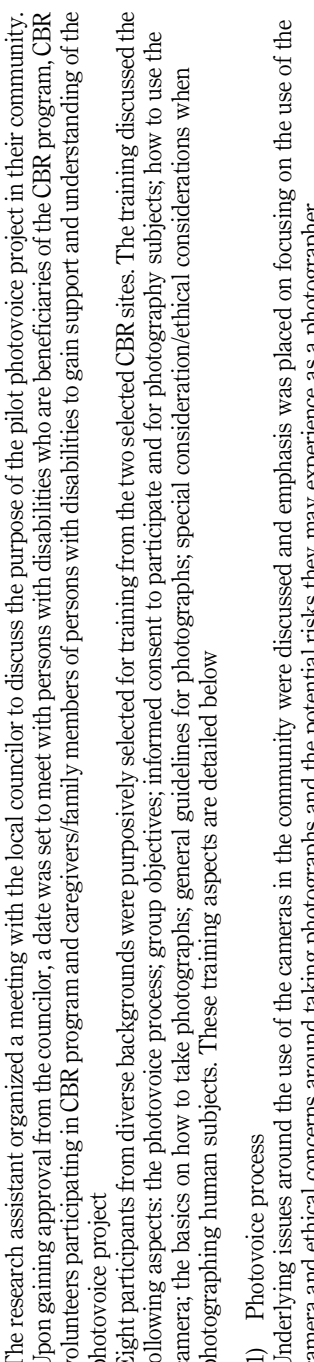

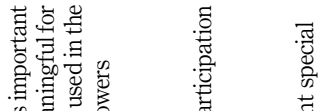

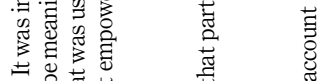

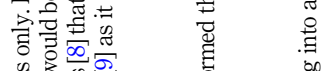

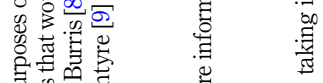

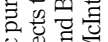

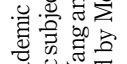

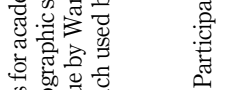

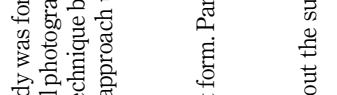

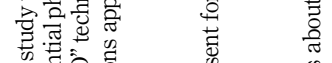
के 品皆 专

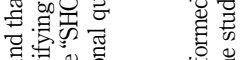
a

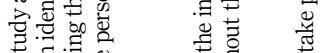
क.

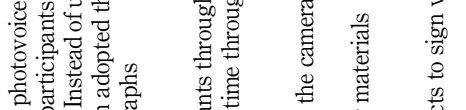

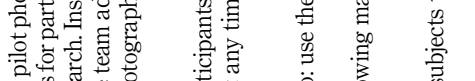

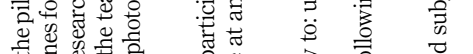

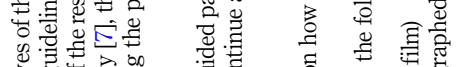
कू

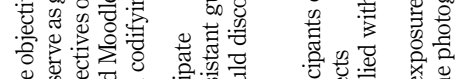

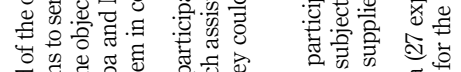

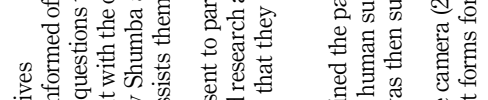

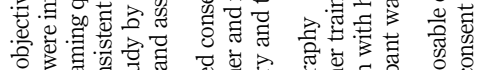

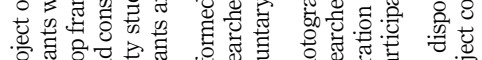

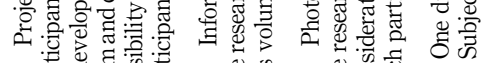

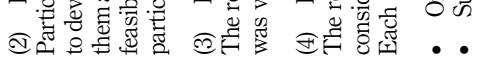




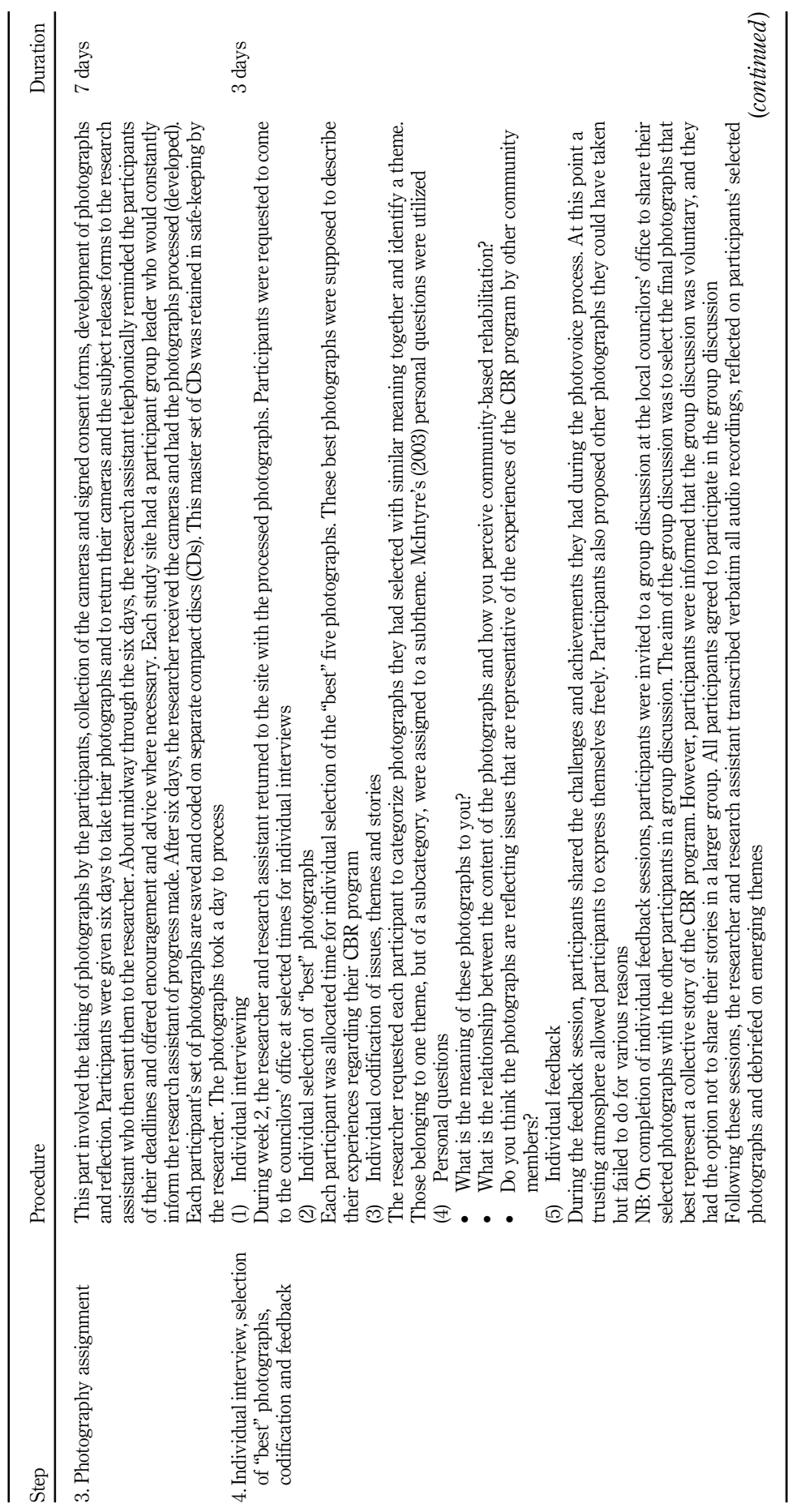

photovoice in evaluating CBR program

253

Table 1. 
JHR
35,3

254

苞

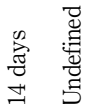

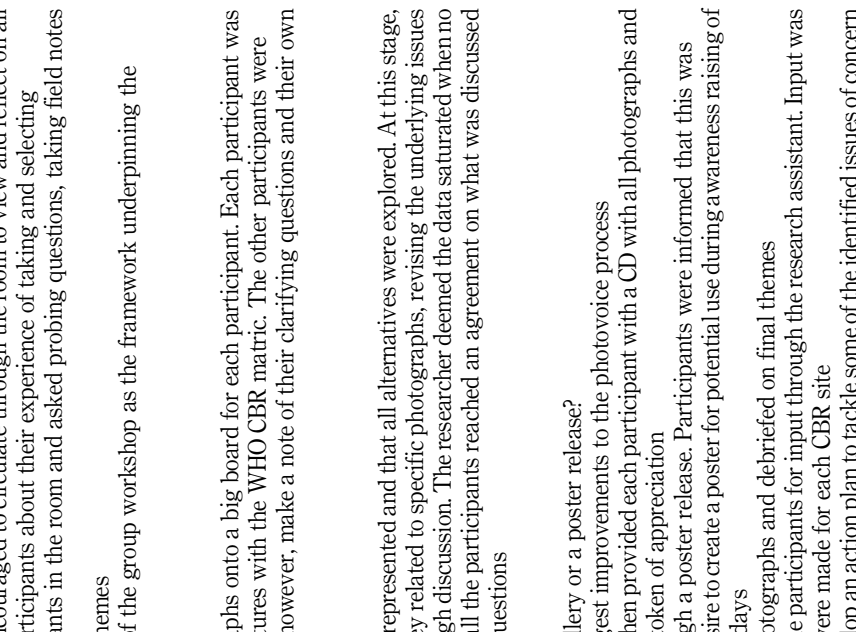

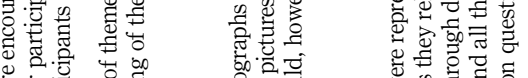

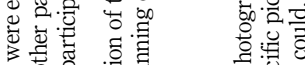

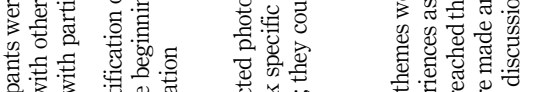

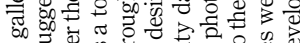

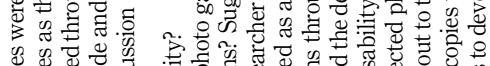

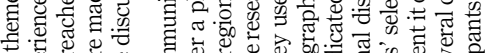

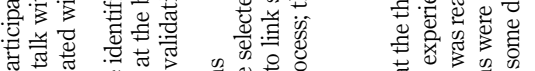

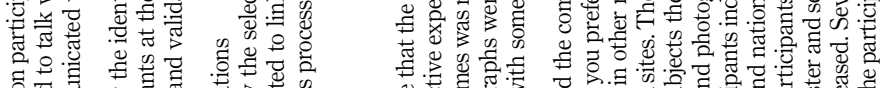

客完

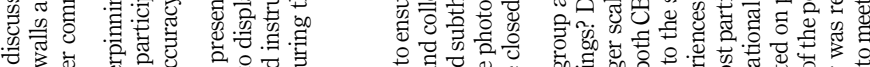

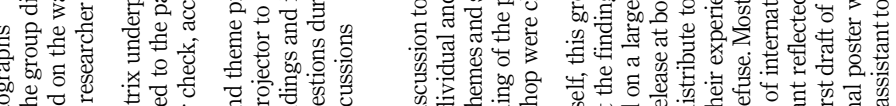

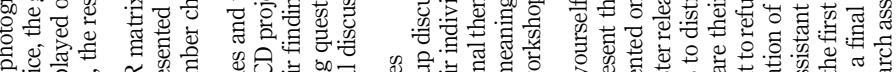

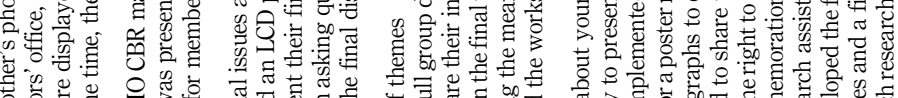

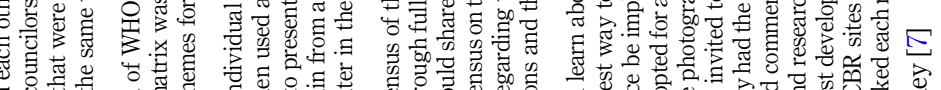

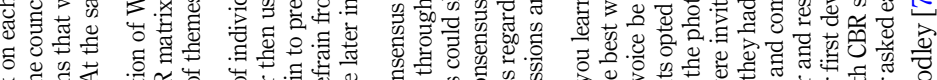

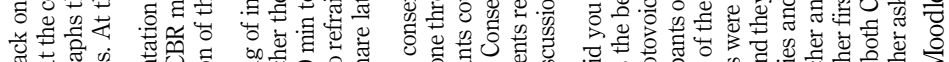

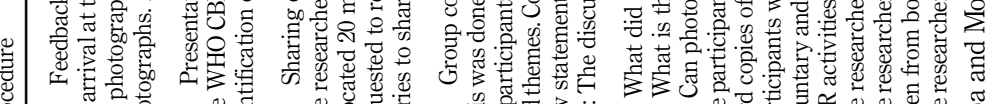

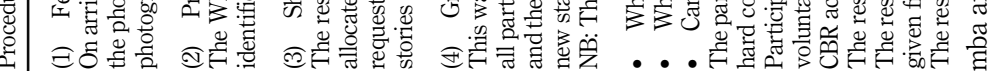

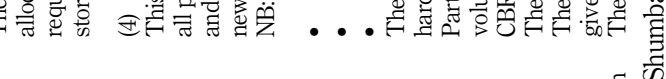

Table 1.

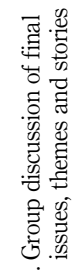

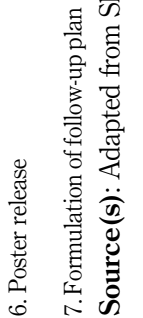


Ethical considerations

Ethics approval was obtained from the Human Sciences Ethics Research Committee of the University of KwaZulu-Natal (Reference No: HSS/0646/015D) and approval to conduct research from the Ministry of Health and Social Services in Namibia (17/3/3).

\section{Qualitative rigor}

Lincoln and Guba's strategies for the qualitative approach including credibility, transferability, dependability and confirmability [10] were used to ensure trustworthiness. Credibility was assured by prolonged engagement; referential adequacy through the use of cameras, tape recorder and field notes; triangulation through the use of photographs, individual interviews, focus group discussions and engagement with different stakeholders. Transferability was ensured using purposive sampling, photographs and thick descriptions of the methodology. Member checks on participants' responses and peer debriefing of themes among authors, recorded audiotapes and photographs, written field notes ensured confirmability. Methodological notes and reflexivity ensured dependability.

\section{Results}

Participant characteristics

All participants were CBR volunteers with some form of disability. Of the initial 16 participants, 12 completed the study (seven in Otavi and five in Stampriet). The reasons for failing to complete the study included losing interest in photography and relocating to other areas during the data collection. Participants' ages ranged from 21 to 77 years and there were more females $(n=10)$ than males $(n=6)$. The majority of participants selected had physical disabilities $(n=12)$, visual impairments $(n=3)$ and only one with mental illness. Most participants were $\mathrm{CBR}$ volunteers participating in CBR programs.

\section{Photovoice method}

The results from the photovoice method are described according to the following sections:

Photography assignment and selection of photographs. A total of 242 photographs were successfully developed from both study areas, and of these, 64 photographs were selected by participants to share during the individual interviewing process. The final photographs that were included for the poster presentation after the group workshop were 10 per each study area.

Participants' experiences. The photovoice method elicited participants' experiences regarding the CBR program and was analyzed utilizing the WHO CBR matrix [11]. Participants took photographs that reflected their positive or negative experiences regarding the CBR program as outlined by the following five themes: health services, education, livelihood, social and empowerment. One photograph could have several themes.

\section{Theme 1: health services}

Participants in both study areas recorded both positive and negative experiences regarding access to health services regarding rehabilitation (Figure 1) and medical services (Figure 2).

\section{Theme 2: education}

Participants at both study sites elicited experiences related to the physical environment and information accessibility (Figure 3).

\section{Use of photovoice in evaluating CBR program}




\section{JHR 35,3}

\section{6}

Figure 1.

Referral for physiotherapy

Figure 2.

Assistance to seek medical services

Figure 3.

Physical and communication accessibility

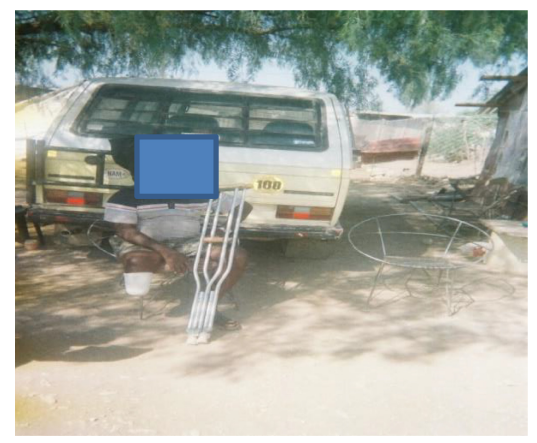

Comments of the participant being:

$C B R$ volunteers referred him for physiotherapy. He has been receiving physiotherapy services and also received a wheelchair... as CBR volunteers we help him with some exercises at home...we feel we are helping him improve his health $(\mathrm{O} 2)$.
Participant's comments being:

I (CBR volunteer) feel sorry and it hurt me that this man can't push his wheelchair and needs assistance every time to get out of his home especially when he is in need of medical treatment. The ambulances at the clinic don't pick up patients even those that are seriously ill. The clinic needs to consider the needs of person with disabilities, especially those who have mobility problems (O6).

\section{Theme 3: livelihood}

Participants expressed experiences about self-employment projects (Figure 4). However, despite some participants conveying positive experiences, some participants in Stampriet voiced concerns with regard to the social housing scheme, which does not take into consideration accessibility issues when building houses for persons with disabilities.

The participant's comment is:

It is so sad that we (persons with a disability) have such a school which can neither enrol a child with a wheelchair nor a child who is deaf. It (the school) does not have ramps for wheelchairs or teachers for deaf children. These children are referred to Mariental or Windhoek where most times they don't have anyone to stay with ..... S(4) 


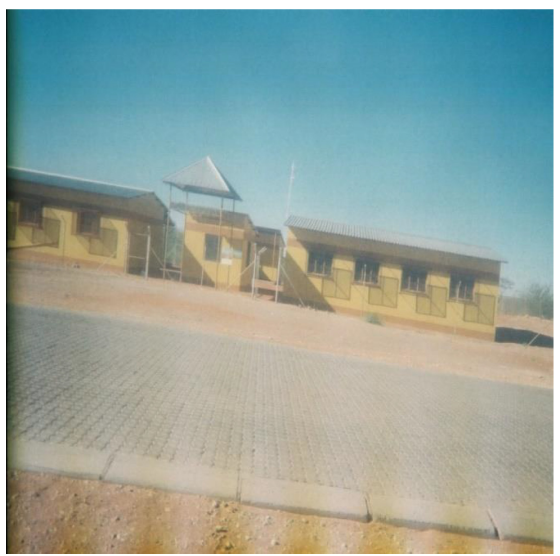

The participant's comment is:

A multipurpose centre is where people rent a space for their businesses. We (CBR volunteers) have facilitated the Council to allow persons with disabilities to showcase their talent. But the rentals at this place are very expensive such that at the moment there is no person with a disability renting space. We want the Council to make this place cheaper to allow everyone including persons with disabilities to start their small businesses (S2).
Use of photovoice in evaluating CBR program

257

Figure 4.

Multipurpose center

\section{Theme 4: social}

Both sites pointed out issues concerning their social life including basic counseling and moral support that CBR volunteers provide. However, some described their experiences regarding lack of personal assistance (Figure 5).

\section{Theme 5: empowerment}

CBR volunteers in both sites are advocating for physical access to public buildings. Participants in Stampriet stated that most persons with disabilities were living in very poor housing conditions due to a lack of representation on local development committees, including the community development committee (Figure 6).

\section{Methodological strengths and weaknesses of the photovoice method}

The capacity of photovoice to elicit the experiences of participants on the CBR program at both study sites was analyzed utilizing the WHO CBR matrix [11]. These experiences were based on the best five photographs that were selected by the participants. The outcomes of

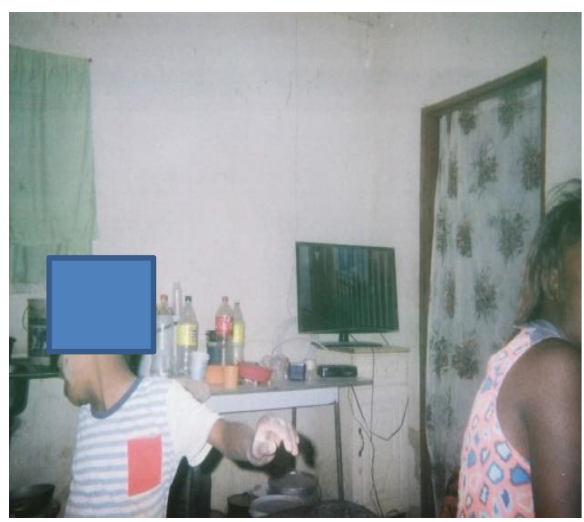

The participant's comment is:

I am taking care of this child with a disability and I also have a disability. He has athetoid cerebral palsy and I have challenges with balance in walking. I can't look for a job because this child needs my attention every minute. I always wish the government can also help persons like us with personal assistance so that we can also be able to seek employment and have time to socialise (O4).
Figure 5.

Personal assistance 


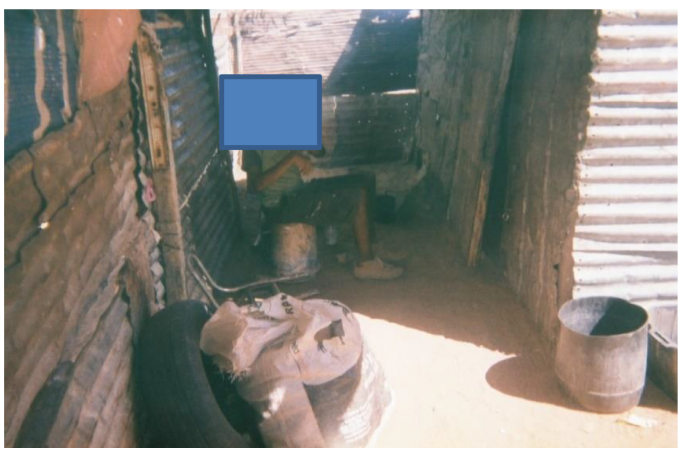

The participant's comment is:

Most persons with disabilities in this area live in poor housing which is not accessible. They are left out of the local council's housing scheme because of lack of representation on the community development committee. We would like the CBR volunteers to advocate for representation of persons with disabilities at the community development committees where these

Figure 6. Poor housing

the photovoice method for each participant (represented by O1-O7 (Otavi) and S1-S8 (Stampriet)) are presented in Table 2.

For example, participant Q1 expressed a positive experience with regard to rehabilitation services (RH), social protection (SP) and advocacy for physical accessibility (APA) but a negative experience with regard to personal assistance (PA). Furthermore, some photographs per participant had more than one theme (Q3) and some participants (Q7, S1, S7) selected less than five photographs.

\section{Discussion}

This study explored the potential use of the photovoice method as an evaluation tool that can be utilized to elicit the experiences of CBR volunteers on the CBR program in Namibia.

(1) Health services

Critical issues identified regarding health were rehabilitation services (physiotherapy, wheelchair assessments, home visits), assistive devices, health promotion (sexual reproductive health education) and water and sanitation. While most areas received positive results, water and sanitation emerged as one area that needs attention. The public toilet systems in both areas were both inaccessible and dirty posing a health hazard especially for persons with visual impairment. The World Report of Disability proposed the use of simple and low-cost solutions for accessible toilets and water-carrying devices [12].

The negative experience regarding assistive devices is mainly a failure to meet the demand.

The study revealed teenage and unwanted pregnancy particularly among persons with mental illness. Literature has revealed that parents often limit sexual talk with their children with disabilities for hygienic purposes [13], yet it has been found that adolescents with physical disabilities are more sexually active than their nondisabled counterparts [14]. Thus, CBR programming in Namibia should place more emphasis on issues of HIV/AIDS and sexual reproduction with extended emphasis on these subjects in WHO CBR guidelines.

(2) Education

Issues elicited were inclusive education (special schools, skilled teachers for the deaf and blind) and lack of accessibility (physical and information) to schools. This study revealed that some schools are still lagging in embracing the principles laid down in this policy. Both physical and information inaccessibility was identified in both study areas as hampering the enrollment of students with disabilities in schools. 


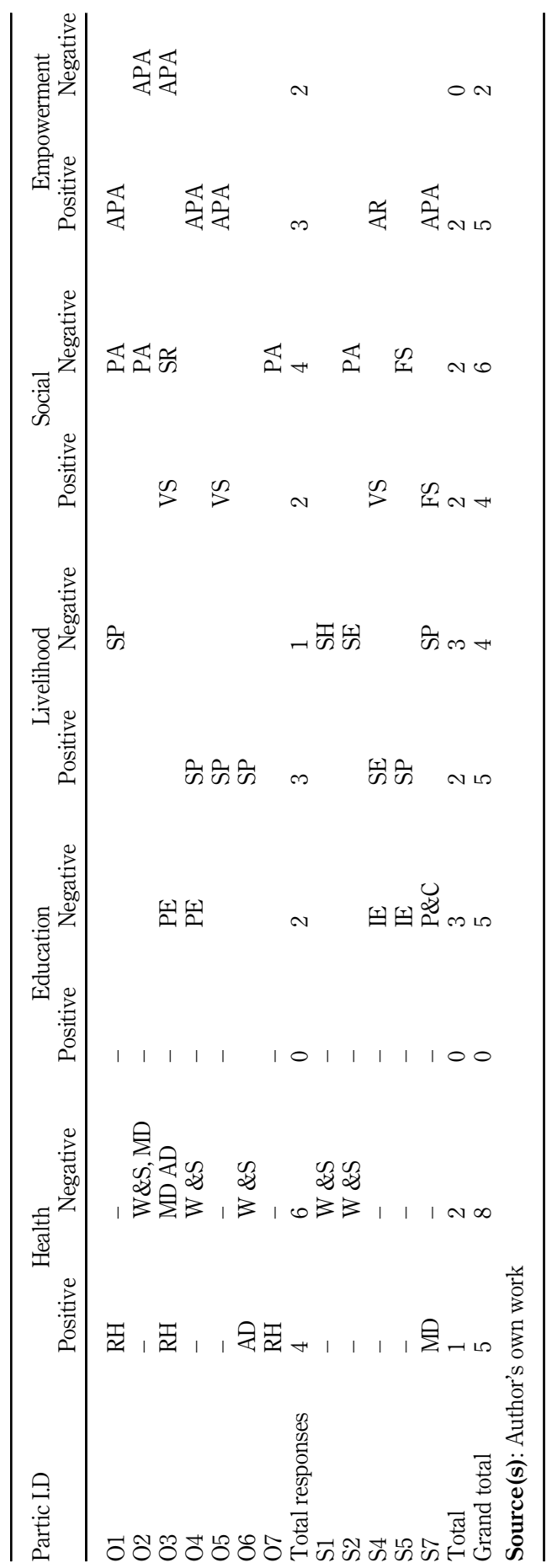

Use of photovoice in evaluating CBR program

259

Table 2. Outcomes of the photovoice process (positive and negative experiences) 
JHR

35,3
The National Statistics Agency [15] reported that $87 \%$ of children with disabilities aged 0-4 years are not attending Early Childhood Development (ECD). Further, the number of children with disabilities aged 0-4 that are not attending ECD programs only increased marginally from 3,359 (2001) to 5,135 (2011) [16].

While the number of children in primary education has been increasing since early 2000 there is a trend of nonprogression into secondary education [16].

This study revealed that there is a critical shortage of special schools with none in the Hardap Region of Namibia. Further, the study revealed that some children with disabilities are turned away because they do not have the teachers with the required skills set for educating these children. To bridge this gap, national OPDs can link with teacher training colleges, to train teachers on how to work with learners with disabilities as is the case in Mozambique [16]. Furthermore, in the absence of these specialist providers, CBR workers can assist teachers in offering support to children [12].

(3) Livelihood

Accessing livelihood opportunities is a key factor in eliminating poverty. Poverty leads to increased disability, which in turn leads to increased poverty. It has been observed that $50.0 \%$ of disabilities are preventable and directly linked to poverty [17].

The main positive experience of the CBR program expressed at both study sites is access to social protection in the form of a disability grant. Although the study indicated a positive experience regarding disability grants, the number of those receiving disability grants may be far from being precise as the definition of disability used by the policy and legal framework of Namibia is not uniform, thus allowing instances of inconsistent application by state doctors [18].

Participants, particularly in Stampriet, expressed dissatisfaction with the lack of inclusion of persons with disabilities in the social housing scheme leading to a lack of knowledge by the municipal authorities on physical accessibility standards. Local OPDs can work closely with local municipalities in providing information on physical accessibilities and can offer practical experiences of persons with disabilities.

\section{(4) Social}

Participants in this study expressed positive experiences regarding family and the CBR volunteer support they obtained through counseling provision. As revealed by the World Report on Disability, in Namibia, of the $67.4 \%$ in need of counseling for parent or family, only $41.7 \%$ received counseling [12].

Most participants expressed the need for the government to provide personal assistance especially for persons with severe and multiple disabilities. Lack of personal assistance deterred some participants from securing employment because of the long hours they spend caring for their children with multiple and severe disabilities. This finding can be attributed to a lack of specific policy provisions regarding personal assistance in the disability policy and legal framework of Namibia [3].

(5) Empowerment

The study revealed that physical accessibility remains poor despite the advocacy initiatives of CBR volunteers at both sites. The lack of physical accessibility can be attributed to a lack of legislation on physical accessibility in Namibia [5].

Participants also expressed dissatisfaction with the lack of representation of persons with disabilities on local development committees including the community development community. This has led to most participants living in poor housing conditions as reported at Stampriet. 
Implications for practice

Photovoice is participatory and hence gives community ownership and empowerment. Evidence from photovoice can enable persons with disabilities to formulate action plans and be able to reach policymakers and justify more funding for CBR programs.

Most experiences elicited on the CBR program through the photovoice method were related to the health component and fewer participants commented on the education component. In both study sites, participants expressed no positive experiences with regard to the education component. Notably, the most negative experiences that were elicited related to the health and social components. This may be attributed to multiple issues of concern including poor accessibility and lack of sexual reproductive health education [14]. Thus, this study demonstrated that photovoice is a valuable method for eliciting experiences of persons with disabilities and can facilitate advocacy efforts through the use of photographs and narratives.

The informal nature of the photovoice method permitted participants to feel relaxed and confident in sharing their photographs and related comments and most appeared to have enjoyed the process. Photovoice is suitable for people who lack confidence in verbally expressing their ideas [8]. Further, the group workshop step empowered participants to share their experiences, expertise and learn from each other [19].

Photovoice allowed the researchers to understand the benefits and challenges of the CBR program from the experiences of persons with disabilities rather than from program managers who might have an obvious bias. Involving persons with disabilities in the research process improved their self-esteem and offered validity to the research process through an unaffected analysis of their life experiences. Giving participants cameras empowered them and boosted their confidence, but also allowed the researchers to understand some social realities of persons with disabilities that are not often accessible to researchers. Such findings, channeled effectively, offer an opportunity to influence decisionmakers in making policy changes aimed at improving CBR programs.

However, it is important to note some methodological challenges that were encountered through this utilization of the photovoice method. The photovoice method did not work for every participant as shown by the failure of some to complete the process. Most participants set out with tremendous enthusiasm but some lost interest in the process. For example, one participant indicated to the research assistant that the process was tiresome and too long to complete. The researcher learned that constant prompting and motivation are needed when the photovoice method is used with persons with disabilities. It is also noteworthy that some participants with visual impairments (low vision) needed assistance with taking photographs.

Some of the methodological challenges that the photovoice process encountered were minor acquiescence (a tendency to agree with the viewpoint of the interviewer) and minor positive response bias (reluctance to say something critical about a particular topic especially in the provision of services) [20]. A study by Shumba and Moodley [7] recommended asking participants to state anything they wished to have photographed if they had been given the opportunity. This was implemented in the current study and allowed some participants to mention some items they thought were difficult to photograph because of cultural sensitivity or for fear of consequences. Furthermore, some participants mentioned that they did not have access to some places during the period of the study due to lack of transport. To this end, it might be a useful adjunct to request participants to share some photographs they took before the photovoice process in cases where they are relevant.

Further, Shumba and Moodley [7] revealed that eliciting experiences of persons with disabilities opened a range of communication problems so we adopted the approach by McIntyre [9] that utilized the personal questions to minimize abstract questions or concepts in the photovoice process. photovoice in
evaluating
CBR program 
JHR

35,3

Notwithstanding the value of photovoice in mitigating communication problems among persons with disabilities, some of the participants had limited vocabulary and limited articulation skills to share their experiences. Thus, the accuracy of interpretations of some photographs was questionable.

The use of the WHO CBR matrix in this study concurs with Grandisson et al. [21], who proposed that the WHO CBR matrix can be an important framework to be incorporated in CBR evaluations.

The involvement of various stakeholders and giving control to persons with disabilities during the photovoice method promoted a "bottom-up" approach providing relevance to CBR evaluation. However, considering the complexity and participatory nature of $\mathrm{CBR}$, it is important to employ mixed methods that can tap into the experiences and knowledge of various stakeholders. One of the objectives of the CBR program is to improve the quality of life of persons with disabilities. Thus, there is a need to integrate photovoice with quality of life assessment tools. The WHOQOL-BREF and the WHOQOL-Dis assessment tools [22] have been utilized to measure the quality of life of persons with disabilities [7]. To this end, further expert validation in the field is recommended to integrate photovoice, WHOQOL-BREF and the WHO CBR matrix.

\section{Limitations}

The use of purposive sampling in selecting both CBR sites and participants limited wider representation of CBR program sites and persons with all disabilities in Namibia, respectively. Also, because of the scope of the study, not all persons with different types of disabilities could be included. Persons with hearing impairment were excluded as none from the research team had basic sign language skills. While persons with hearing impairment may be good with photography, they may have challenges in a clear articulation of their experiences [23], thus requiring them to be provided with reasonable accommodation including sign language interpreters.

Another group that was excluded were persons with intellectual and severe disabilities due to the extensive assessments needed to ensure that their interests and ethical concerns were adequately considered. Future research could provide reasonable accommodation for such groups of persons with disabilities. The photovoice method can be modified to suit specific requirements of disability groups. For example, including persons with mental illness and visual impairments may require an assistant. Additionally, deaf persons may require a sign language interpreter.

\section{Conclusion}

The main aim of this study was to investigate the potential of photovoice in eliciting the experiences of CBR volunteers on the CBR program in Namibia. The findings have not only highlighted the experiences of CBR volunteers on the CBR programs but also demonstrated that photovoice can be used to generate an adequate representation of the benefits and challenges of the CBR program.

This study has not only increased the awareness of the benefits and challenges experienced by persons with disabilities but has increased the awareness of disability issues to policymakers and implementers of the CBR program and potentially the wider public.

Further, research within CBR programming and service provision could consider measuring the changes in quality of life from CBR initiation over some time in new areas where CBR initiation is still needed. Longitudinal studies will help measure the effect of CBR on health and social services expenditure. A national evaluation of the Namibia CBR program could consider a mixed-method evaluation, integrating the findings of the photovoice method with other evaluation methods including the WHOQOL-BREF and WHOQOL-Dis. 


\section{References}

Use of

1. Namibia, Ministry of Health and Social Services. Community based rehabilitation guidelines. Windhoek: Ministry; 2013.

2. Government Republic of Namibia. National policy on disability. Windhoek: Ministry Office; 1997.

3. Shumba TW, Moodley I. Review of policy and legislative framework for disability services in Namibia. S Afr J Physiother. 2018; 74(1): 399. doi: 10.4102/sajp.v74i1.399.

4. Duncan M, Sherry K, Watson R. Disability and rurality. In: Lorenzo T, editor. Intentions, pillars, and players, disability innovations Africa. Cape Town, CA: School of Health and Rehabilitation Sciences, University of Cape Town; 2011: 30-4.

5. Shumba TW, Moodley I. Implementation of disability policy framework in Namibia: a qualitative study. S Afr J Physiother. 2018; 74(1): 400. doi: 10.4102/sajp.v74i1.400.

6. Shumba TW, Moodley I. Part 1: a review of using photovoice as a disability research method: implications for eliciting the experiences of persons with disabilities on the Community Based Rehabilitation programme in Namibia. Afr J Disabil. 2018; 7: 418. doi: 10.4102/ajod.v7i0.418.

7. Shumba TW, Moodley I. Part 2: the feasibility of utilising photovoice method and the World Health Organization Quality of Life instrument in evaluating the Community-Based Rehabilitation programme in Namibia: a pilot study. Afr J Disabil. 2018; 7: 419. doi: 10.4102/ajod.v7i0.419.

8. Wang C, Burris MA. Photovoice: concept, methodology, and use for participatory needs assessment. Health Educ Behav. 1997 Jun; 24(3): 369-87. doi: 10.1177/109019819702400309.

9. McIntyre A. Through the Eyes of Women: photovoice and participatory research as tools for reimagining place. Gend Place Cult. 2003; 10(1): 47-66. doi: 10.1080/0966369032000052658.

10. Lincoln Y, Guba E. Naturalistic inquiry. Beverly Hills, CA: Sage; 1985.

11. World Health Organization [WHO], UNESCO, International Labour Organization [ILO], International Disability and Development Consortium [IDDC]. Community based rehabilitation guidelines introductory booklet. Geneva: WHO; 2010.

12. World Health Organization [WHO], World Bank. World report on disability. Geneva: WHO; 2011.

13. Wazakili M, Mpofu R, Devlieger P. Experiences and perceptions of sexuality and HIV/AIDS among young people with physical disabilities in a South African Township: a case study. Sex Disabil. 2006 Sum; 24(2): 77-88. doi: 10.1007/s11195-006-9006-8.

14. Maart S, Jelsma J. The sexual behaviour of physically disabled adolescents. Disabil Rehabil. 2010; 32(6): 438-43. doi: 10.3109/09638280902846368.

15. Namibia Statistics Agency. Namibia national housing and population census. Windhoek: Namibia Statistics Agency; 2011.

16. Schurmann E. Training disabled teachers in Mozambique. [cited 2019 September]. Available at: https://www.eenet.org.uk/enabling-education-review/enabling-education-10/newsletter-10/10-15/.

17. Disability, poverty and development. [cited 2017 March 20]. Available at: http://www.makedevelopment inclusive.org/docsen/DFIDdisabilityPovertyDev.pdf.

18. International Labour Office. Namibia social protection floor assessment report. Geneva: International Labour Office; 2014.

19. Jurkowski JM, Paul-Ward A. Photovoice with vulnerable populations: addressing disparities in health promotion among people with intellectual disabilities. Health Promot Pract. 2007 Oct; 8(4): 358-65. doi: 10.1177/1524839906292181.

20. Antaki C, Young N, Finlay M. Shaping clients' answers: departures from neutrality in care-staff interviews with people with a learning disability. Disabil Soc. 2002; 17(4): 435-55. doi: 10.1080/ 09687590220140368.

21. Grandisson M, Hebert M, Thibeault R. A systematic review on how to conduct evaluations in community-based rehabilitation. Disabil Rehabil. 2014; 36(4): 265-75. doi: 10.3109/09638288.2013. 785602 . 
22. World Health Organization [WHO]. Programme on mental health. WHOQOL-BREF user manual. Geneva: WHO; 1998.

23. Jurkowski JM. Photovoice as participatory action research tool for engaging people with intellectual disabilities in research and program development. Intellect Dev Disabil. 2008 Feb; 46(1): 1-11. doi: 10.1352/0047-6765(2008)46[1:Papart]2.0.Co;2.

Tonderai Washington Shumba can be contacted at: shumbatw@gmail.com

For instructions on how to order reprints of this article, please visit our website: www.emeraldgrouppublishing.com/licensing/reprints.htm Or contact us for further details: permissions@emeraldinsight.com 